\title{
Humic Acid Removal by Electrocoagulation Process from Natural Aqueous Environments
}

\author{
Hadi Rezaei ${ }^{1}$, Mohammad Reza Narooie ${ }^{2}$, Rasoul Khosravi, Mohammad Javad Mohammadi, \\ Hooshmand Sharafi ${ }^{5}$ Hamed Biglari ${ }^{6, *}$ \\ ${ }^{1}$ Environmental Health Research Center, Kurdistan University of Medical Sciences, Sanandaj, Iran. \\ ${ }^{2}$ Department of Environmental Health, School of Public Health, Iranshahr University of Medical \\ Sciences, Iranshahr, Iran. \\ ${ }^{3}$ Social Determinants of Health Research Center, Department of Environmental Health Engineering, \\ School of Health, Birjand University of Medical Sciences, Birjand, Iran. \\ ${ }^{4}$ Department of Environmental Health Engineering, School of Public Health AND Environmental \\ Technologies Research Center, Ahvaz Jundishapur University of Medical Sciences, Ahvaz, Iran. \\ ${ }^{5}$ Students Research Committee, Kermanshah University of Medical Sciences, Kermanshah, Iran. \\ ${ }^{6}$ Department of Environmental Health Engineering, School of Public Health, Gonabad University of \\ Medical Sciences, Gonabad, Iran. \\ *E-mail: Biglari.h@gmu.ac.ir
}

Received: 9 August 2017 / Accepted: 29 December 2017 / Published: 5 February 2018

Humic acid results in formation of highly toxic and carcinogenic byproducts during the disinfection process of water by chlorine. In this study, removal of industrial humic acid from artificial and natural aqueous media is investigated using electrocoagulation process. To reach the goal, first, humic acidcontaminated water samples with concentrations of $20 \mathrm{mg} / \mathrm{L}$ were prepared in a reactor with the effective volume of $1 \mathrm{~L}$, equipped with iron electrodes. Then, the effects of $\mathrm{pH}$ ( 2 up to 9) and electric potential of $30 \mathrm{~V}$ was studied by measurement of UV radiation absorption and total organic materials methods, on the coagulation process in removal of humic acid within $80 \mathrm{~min}$. According to the results of this study, the best efficiency in removal of humic acid was obtained as $92.69 \%$ by electrochemical process when the parameters were adjusted as; potential difference of $50 \mathrm{~V}, 80 \mathrm{~min}$ reaction time, $\mathrm{pH}$ 5 , and electric conductivity of $3000 \mu \mathrm{S} / \mathrm{cm}$. In the optimum condition, the efficiency of humic acid removal from natural water was obtained as $68.8 \%$. The results indicated that, the electrochemical process equipped with iron electrodes could remove humic acid from aqueous media, efficiently.

Keywords: Humic Acid, Electrocoagulation process, Aqueous Environments, Natural Organic Material, Dissolved Organic Material 


\section{INTRODUCTION}

Humic acid compounds constitute the major part of dissolved organic materials in natural water [1]. In fact, $90 \%$ of dissolved organic carbon in all natural water samples may be attributed to this compound [2]. Humic acid is a large and complex molecule, the structure of which consists of compounds such as carboxylic acid, and phenolic groups. At $\mathrm{pH}$ values above 2, these compounds are found in dissolved and negatively charged forms in underground and surface water sources up to 20 $\mu \mathrm{g} / \mathrm{L}$ and $30 \mathrm{mg} / \mathrm{L}$, respectively [3, 4]. The humic acid compounds are not toxic on their own, however, they raise secondary problems when using chlorine for drinking water treatment. These problems include creating adverse aesthetic effects corresponding to color, taste, and odor in drinking water [5, 6], transportation of toxic metals [3, 7], Reducing the desired effect of water treatment processes on the pollution removal [8,9], corrosion of metallic facilities [10-12], adverse effects on the coagulation [13], adsorption, processes [14], adverse effect on the functionality of membranes [15], contribution to regrowth of microorganisms in water supplying systems and water storage tanks [16, 17], increasing the amount of disinfecting agents utilization in water treatment processes, and more importantly, during the water disinfection process, humic acid compounds may react with the disinfecting agents and result in production of over 600 types of disinfecting agent byproducts such as THMs and HAAs which could cause cancers naming bladder and intestine cancers as the most important ones [18-19]. Currently, the paramount reason stated for removal of these compounds from water is acetic acids (HAAs), the threshold limit values of which are determined as $60 \mu \mathrm{g} / \mathrm{L}$ and 80 $\mu \mathrm{g} / \mathrm{L}$ in drinking water at the first stage of applying the regulations and $30 \mu \mathrm{g} / \mathrm{L}$ and $40 \mu \mathrm{g} / \mathrm{L}$ at the second sage by United States Environmental Protection Agency [20]. The World Health Organization has also set the threshold limit value of THMs in drinking water as $100 \mu \mathrm{g} / \mathrm{L}$ [21]. Furthermore, the Institute of Standards and Industrial Research of Iran determines the threshold limit values for bromoform, dibromochloromethane, bromodichloromethane, and chloroform in drinking water as 0.1, 0.1, 0.06, and $0.3 \mathrm{mg} / \mathrm{L}$, respectively [22]. Considering the fact that, according to the studies conducted within the past 10-20 years, the presence of this compound has shown an increasing trend in drinking water sources, they must be removed from drinking water sources before the disinfection process [19, 23, 24]. Chemical coagulation, precipitation, oxidation, adsorption, ion exchange and filtration by membranes may be named as some of the methods of the removal of these compounds from aqueous media [25-29]. In this regard, removal of these contaminants by electrochemical process has attracted wide attention in different fields of water and wastewater treatment [30, 31]. This process functions based on electrodes being under powerful electric field and redox reactions, leading to removal of the contaminants by adsorption, neutralization of electric charge, and complex formation in aqueous media $[32,33]$. To date, the removal of organic material and humic acid from aqueous media has been investigated in numerous studies [34-36]. However, the efficiency of each process may differ according to the nature of humic acid in certain regions. On the other hand, data about the application of iron electrode for removal of organic humic acid in electrochemical process is limited and inadequate. This study is conducted to resolve the ambiguities and its undetermined boundaries as well as providing a scope and facilitating the use of this method in treatment of the water of Zahedan to remove the humic acid from aqueous media by coagulation process. 


\section{MATERIALS AND METHODS}

All commercial compounds including sodium hydroxide, perchloric acid, and potassium chloride were the chemicals acquired from Merck Company of Germany. The electrochemical unit instruments consisted of a Plexiglass container of $1 \mathrm{~L}$ volume equipped with four iron plate electrodes submerged in a container of $11 \times 11 \mathrm{~cm}$ dimensions with a buccal type bottom and inter-plate distances of $2 \mathrm{~cm}$. These devices were connected to the transformer (power supply) by bipolar connection method to provide a potential difference of $50 \mathrm{~V}$. Furthermore, to obtain a homogeneous aqueous medium under the process, the samples were stirred using a magnetic stirrer with a constant rate [70 $\mathrm{rpm}$ ). The solution of humic acid was prepared by dissolving extracted powder humic acid in a 0.1 normal solution of sodium hydroxide under vigorous stirring for several hours. Then for obtaining the optimum conditions for $\mathrm{pH}$, potential difference, and reaction time, the experiments were performed.

Zahedan is in the center of Sistan and Baluchistan and the biggest province of Iran $\left(33^{\circ} 30^{\prime} \mathrm{N}\right.$ $48^{\circ} 42^{\prime} \mathrm{E}$ ). The weather in this city is dry and seasonal streams, with an average annual rainfall of only $50 \mathrm{ml}$ per year. The city's drinking water is provide from the semi-wells (Chah-Nime) located on the north side of the province (N3047 E6135) and water of it prepared by drainage from the rivers of Afghanistan. The quality profile of the sample is provided in table 1. Humic acid was extracted from the real sample by decreasing the acidity down to below 2 using concentrated hydrochloric acid, and then the extracted amount was measured by TOC analyzer model ANATOC Series II [37, 38]. To perform the experiments, each of the synthetic samples were prepared with $20 \mathrm{mg} / \mathrm{L}$ humic acid. The $\mathrm{pH}$ values were adjusted to $3,5,7$, and 9 using 0.1 and 1 normal perchloric acid and sodium hydroxide solutions (measured by Denver Ultra basic-UB10 $\mathrm{pH}$ meter made in USA), and the electric conductivity was adjusted to $1000,1500,2000$, and $3000 \mu \mathrm{S} / \mathrm{cm}$ by addition of 0.5 normal potassium chloride $(\mathrm{KCl})$ solution (measured by TWT-Cond 1310 conductivity meter made in Germany). Following injection of the prepared samples into the buccal container, the power supply was turned on and the experiments begun. During the reaction, the sampling took place with appropriate volumes for certain experiments from the middle of the buccal container. Following the sampling process and necessary work ups on the samples, the rates of the absorbed UV light and total organic compound in the samples were determined instantly using a UV-Vis T80 spectrophotometer according to the following equation [39]: and using TOC Analyzer model ANA TOC Series II, respectively.

$[\mathrm{HA}]=30.48 \times$ ABS-2.0549, $\mathrm{r}=0.9918$

At the end of the reaction $(80 \mathrm{~min})$, the acidity and ultimate temperature of the aqueous media were also recorded. In addition, the electrodes were washed and dried at $105{ }^{\circ} \mathrm{C}$ in a hot air oven following being treated with $1 \mathrm{~N}$ perchloric acid for $30 \mathrm{~min}$, and finally weighted and recorded. To overcome the decrease of the volume of aqueous medium during the electrocoagulation process due to the evaporation resulted from the increase of temperature, the reduced amount was measured at specific time intervals and the very same amount of water appropriate with the sample type under the experiment was added to the medium [40]. This process cooled the medium slightly in addition to rehabilitation of the lost volume. Finally, according to the results obtained from the experiments, the corresponding diagrams for each of the $\mathrm{pH}$, reaction time, potential difference, and electric conductivity parameters were plotted and other than comparing these diagrams to each other, the best, 
optimum, and the highest efficiency observed in removal of humic acid among all of the experiments has been reported in this study. It should be noted that, to evaluate the effect of the above process on the real water sample provided from Chah-Nime surface water source of Zahedan, the efficiencies of the removal of sulfate, nitrate, hardness and fluoride as well as the humic acid extracted from real water sample were measured and reported. In this study, all of the experiments were performed according to the standard methods provided in Standard Methods in Examination of Water and Wastewater book and repeated twice [41].

Table 1. Zahedan treatment plant raw water quality

\begin{tabular}{|cc|cc|cc|}
\hline Parameters & $(\mathbf{m g} / \mathbf{l})$ & Parameters & $\mathbf{( m g / l )}$ & Parameters & (mg/l) \\
\hline $\mathrm{NO}_{3}{ }^{-}$ & 11.81 & $\mathrm{pH}$ & 7.78 & $\mathrm{TH}$ & 580.12 \\
\hline $\mathrm{HCO}_{3}^{-}$ & 188.01 & $\mathrm{UV}_{254} \mathrm{~nm}, \mathrm{~cm}-1$ & 0.819 & $\mathrm{PO}_{4}^{-}$ & 0.093 \\
\hline $\mathrm{CO}_{3}^{--}$ & 6.67 & $\mathrm{TOC}$ & 7.12 & Temp ${ }^{\circ} \mathrm{C}$ & 18 \\
\hline $\mathrm{Ca}^{++}$ & 45.28 & $\mathrm{NO}_{2}^{-}$ & 0.008 & Total alkalinity $\left(\mathrm{CaCO}_{3}\right)$ & 194.68 \\
\hline $\mathrm{Mg}^{++}$ & 32.50 & $\mathrm{SO}_{4}^{-}$ & 155 & Temporary hardness $\left(\mathrm{CaCO}_{3}\right)$ & 194.35 \\
\hline $\mathrm{Na}^{+}$ & 106.94 & $\mathrm{Cl}^{-}$ & 106.05 & Total hardness $\left(\mathrm{CaCO}_{3}\right)$ & 246.94 \\
\hline $\mathrm{K}^{+}$ & 4.94 & $\mathrm{~F}$ & 0.48 & NTU & 6.09 \\
\hline $\mathrm{EC}\left(\mathrm{u}^{-} / \mathrm{cm}\right)$ & 906.44 & $\mathrm{TDS}$ & 580.12 & Humic acid & 2.48 \\
\hline
\end{tabular}

\section{RESULTS AND DISCUSSION}

\subsection{Effect of retention time}

Figure 1A demonstrate the variation of the removal efficiency of humic acid at different reaction times and $\mathrm{pH}$ values. The highest removal efficiency is obtained as $93 \%$ at $\mathrm{pH} 5$ and $80 \mathrm{~min}$. At 80 min reaction time, the maximum removal efficiency is achieved at $\mathrm{pH}$ values equal to $8,7,3$, and 5, respectively. Figure 1B illustrates the removal efficiency variations at different reaction times and electric conductivities. Figure $1 \mathrm{~A}$ indicates that, the maximum removal efficiency is achieved as 93\% at $80 \mathrm{~min}$ and $3000 \mu \mathrm{s} / \mathrm{cm}$ EC. Matilainien et al. [19], presumed the self-degradation of humic acid and formation of clots as well as improvement in the coagulation process as the reasons for the enhanced removal efficiency at longer reaction times. FENG et al. [35], in their studies, reported the higher induced current between the two electrodes as the cause of high efficiency at higher electric conductivities. The results of current study are in complete agreement with the above mentioned studies. 

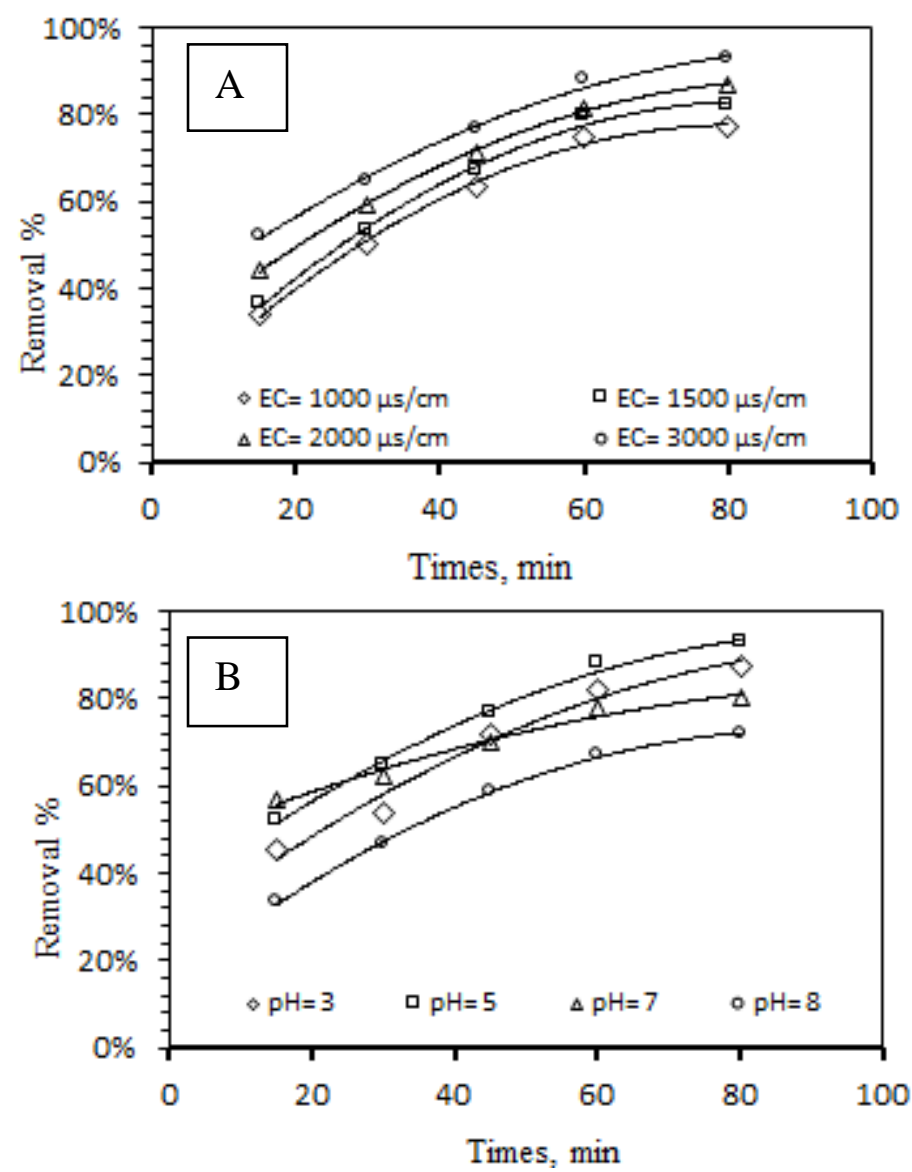

Figure 1. HA removal in different electrical conductivity (A), HA removal in different $\mathrm{pH}$ (B) (EC $3000 \mu \mathrm{S} / \mathrm{cm}, \mathrm{HA} 20 \mathrm{mg} / \mathrm{l}, 50 \mathrm{~V}$ )

\subsection{Effect of Electric Conductivity}

Figure 2A presents the variations of the utilized iron electrode weight at different $\mathrm{pH}$ values and electric conductivities. Figure $2 \mathrm{~A}$ depicted that, upon the increase of electric conductivity, the weight consumption of iron electrodes escalated. Figure 2B demonstrated the energy consumption rate and removal efficiency of humic acid at different electric conductivities. Figure $2 \mathrm{~B}$ shows that with the increase of electricity consumption, the removal efficiency increases as well. The efficiency was about $93 \%$ of the consumed energy equal to $1.71 \mathrm{~kW} / \mathrm{h}$ for every gram of humic acid per cubic meter at electric conductivity of $3000 \mu \mathrm{s} / \mathrm{cm}$. Figure $2 \mathrm{C}$ shows the consumed electrode weight variations and the removal efficiency of humic acid at different electric conductivities. Figure $2 \mathrm{C}$ demonstrate a direct relationship between the electrode weight consumption and improvement in the removal efficiency. As can be observed, the efficiency was about $93 \%$ and iron electrode consumption rate was equal to 0.19 $\mathrm{kg}$ for every gram of humic acid per cubic meter at electric conductivity of $3000 \mu \mathrm{s} / \mathrm{cm}$. Koparal et al. [42], construed the higher formation of coagulants as a result of the release of more dissolved iron ions in aqueous media as the reason for their observations. In addition to formation of coagulants, the increase of bubble formation resulted from release of hydrogen gas escalates the sizes of the formed clots which in turn leads to improvement of the efficiency in electrocoagulation process. 

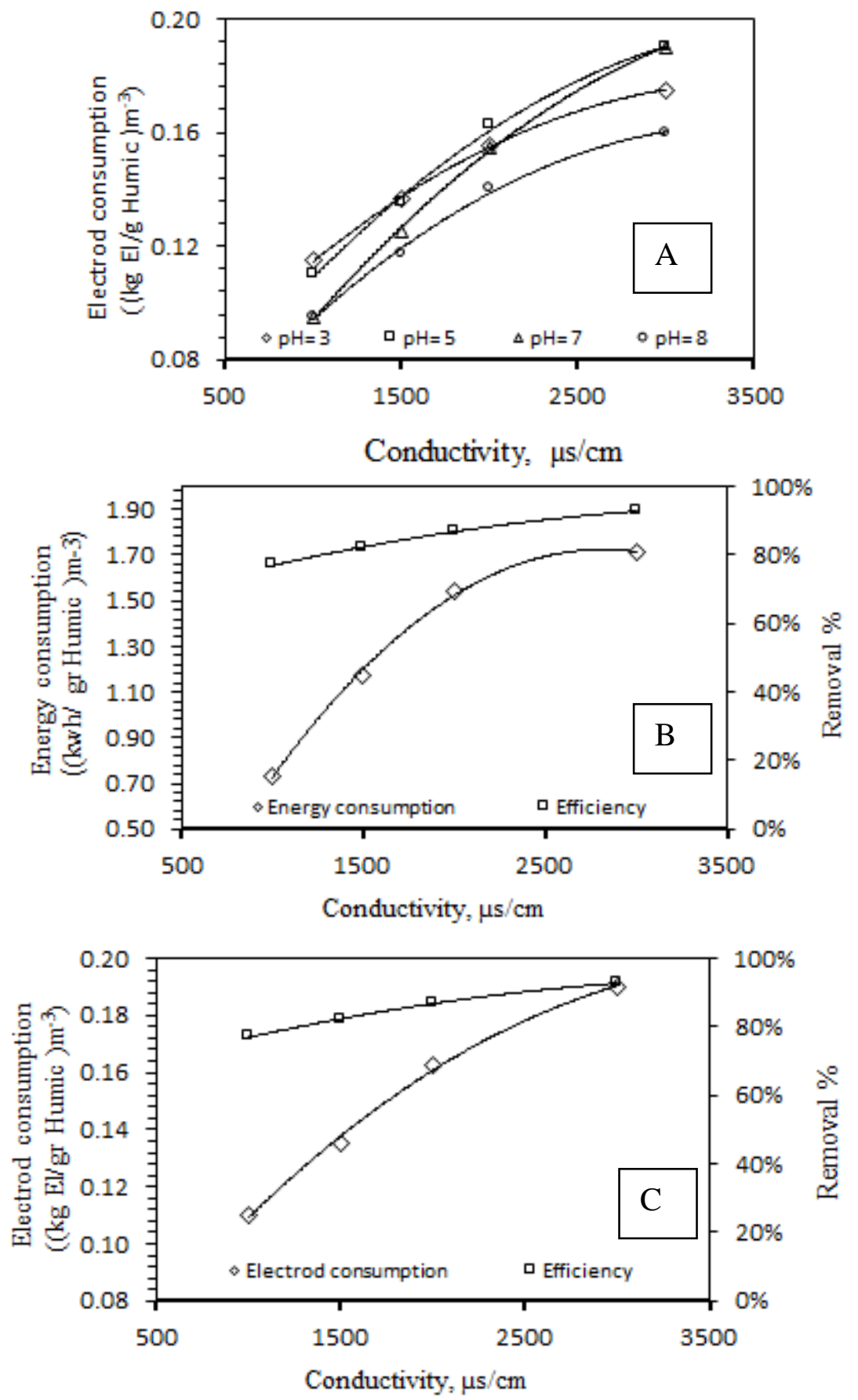

Figure 2. Metal consumption in different $\mathrm{pH}$ and different electrical conductivity (A), Electrical consumption in different electrical conductivity (B), Metal consumption in different electrical (C) (EC $3000 \mu \mathrm{S} / \mathrm{cm}, \mathrm{HA} 20 \mathrm{mg} / \mathrm{l}, 50 \mathrm{~V}, \mathrm{pH}$ 5, Time 80)

These obtained results are in good agreement with many studies [43-45]. The removal efficiencies of other parameters such as sulfate $(46.17 \%)$, hardness $(46.17 \%)$, fluoride $(18.84 \%)$, and nitrate $(25.87 \%)$ were resulted from electrocoagulation process which were in excellent agreement with the results achieved in the investigations of Emamjomeh et al. [45]. 


\subsection{Effect of temperature}

Figure 3 illustrates the variations of the ultimate temperature of the aqueous medium under the process at different $\mathrm{pH}$ values and electric conductivities. Figure 3 depicts that, temperature of the medium declined at first when increasing the electric conductivity from $1000 \mu \mathrm{s} / \mathrm{cm}$ to $2000 \mu \mathrm{s} / \mathrm{cm}$, and then enhanced, remarkably. The highest temperature was observed as $37{ }^{\circ} \mathrm{C}$ at electric conductivity of $3000 \mu \mathrm{s} / \mathrm{cm}$ and $\mathrm{pH} 5$. The minimum and maximum initial temperatures of the aqueous medium before starting the process were recorded as 14.90 and $19.30{ }^{\circ} \mathrm{C}$, respectively. The mean values and the standard deviations were also obtained as 17.24 and 1.26, respectively. Bazrafshan et al. [40], presumed the increase of temperature as one of the factors effective on improvement of the removal efficiency in electrocoagulation process that is in agreement with the results of this study.

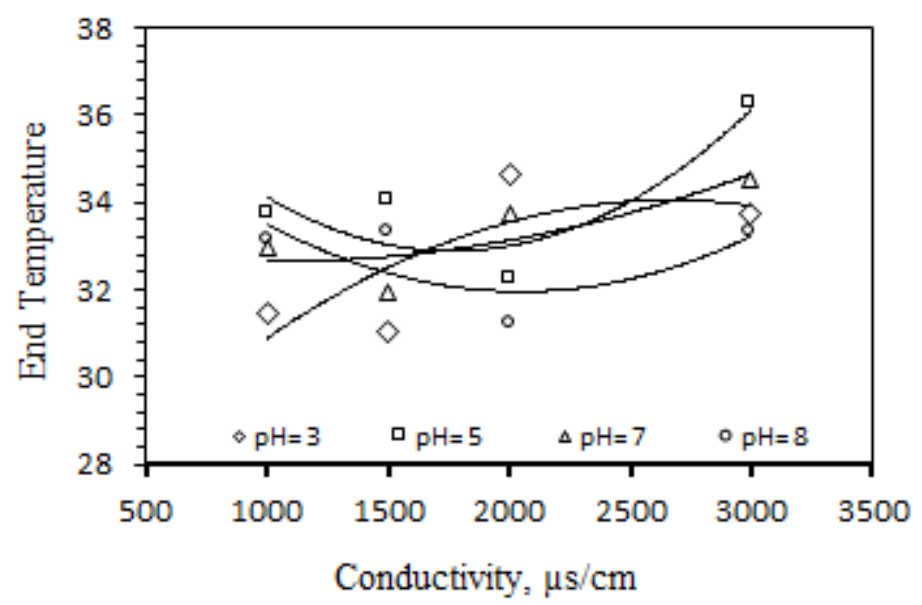

Figure 3. End Temperature in different $\mathrm{pH}$ and different electrical conductivity (EC $3000 \mu \mathrm{S} / \mathrm{cm}$, HA $20 \mathrm{mg} / \mathrm{l}, 50 \mathrm{~V}$, Time 80)

\subsection{Effect of $p H$}

To date, myriad number of studies have been conducted regarding the effect of initial $\mathrm{pH}$ variations on the removal rate of the contaminants in electrocoagulation process and in each of the important and tangible effect of these parameters on the removal rate of the contaminants has been mentioned [37, 44]. Figure 4A shows the variations of ultimate $\mathrm{pH}$ of the aqueous medium under the process against the initial $\mathrm{pH}$ values. Figure $4 \mathrm{~A}$ demonstrated that following the application of iron electrode increased the $\mathrm{pH}$ of the medium under the process, in a way that an initial $\mathrm{pH}$ of 5 reaches up to 8 at the end of the process. Figure 4A furthermore indicates that the removal efficiency of humic acid declines remarkably at high $\mathrm{pH}$ values. Figure $4 \mathrm{~B}$ illustrates the $\mathrm{pH}$ variations of the aqueous medium under the process compared to the initial $\mathrm{pH}$ values and different electric conductivities. Figure 4B revealed that the maximum removal efficiency of humic acid was $93 \%$ at pH 5 and EC $3000 \mu \mathrm{s} / \mathrm{cm}$. The minimum efficiency was obtained as $62 \%$ at $\mathrm{pH} 8$ and $\mathrm{EC} 1000 \mu \mathrm{s} / \mathrm{cm}$. Furthermore, figure $4 \mathrm{~B}$ exhibited that $\mathrm{pH}$ variations increased by enhancing the electric conductivity, and the increasing rate of $\mathrm{pH}$ was remarkable. Figure $4 \mathrm{C}$ depicts the variations of the energy consumption at 
different $\mathrm{pH}$ values and electric conductivity. Figure $4 \mathrm{C}$ indicates that with the increase of continuous electric conductivity the energy consumption increases. Figure 4C shows that, though energy and electrode weigh consumption at $\mathrm{pH}$ values of 7 and 8 is almost equal to those at $\mathrm{pH}$ values of 3 and 5 , removal efficiency of humic acid decreases at former values compared to the later ones. Feng et al. [35], and Koparal et al. [42], attributed the reason to the increased solubility of humic acid in aqueous media at higher $\mathrm{pH}$ values. Matilainen et al. [1419 in their studies reported that the $\mathrm{pH}$ variations at electrocoagulation process is caused by increase of hydrogen generated from cathode electrode which is released as a gas. Since the $\mathrm{pH}$ value is a function of the presence of compound such as carbon dioxide and organic acids derived from Soil Humus, Koparal et al. [42], assign the variations of the ultimate $\mathrm{pH}$ values to the release of carbon dioxide $\left(\mathrm{CO}_{2}\right)$ from the medium under the process and resulted from combination of hydrogen gas bubbles. In this study, by application of iron electrode, the removal efficiency of organic humic acid in the aqueous medium under the process occurred at $\mathrm{pH}$ values from 4.5 to 7 , which is in good agreement with the results of the above studies. The removal efficiency rates were obtained as $92.69 \%$ and $87.45 \%$ at initial $\mathrm{pH}$ values of 5 and 3, respectively.
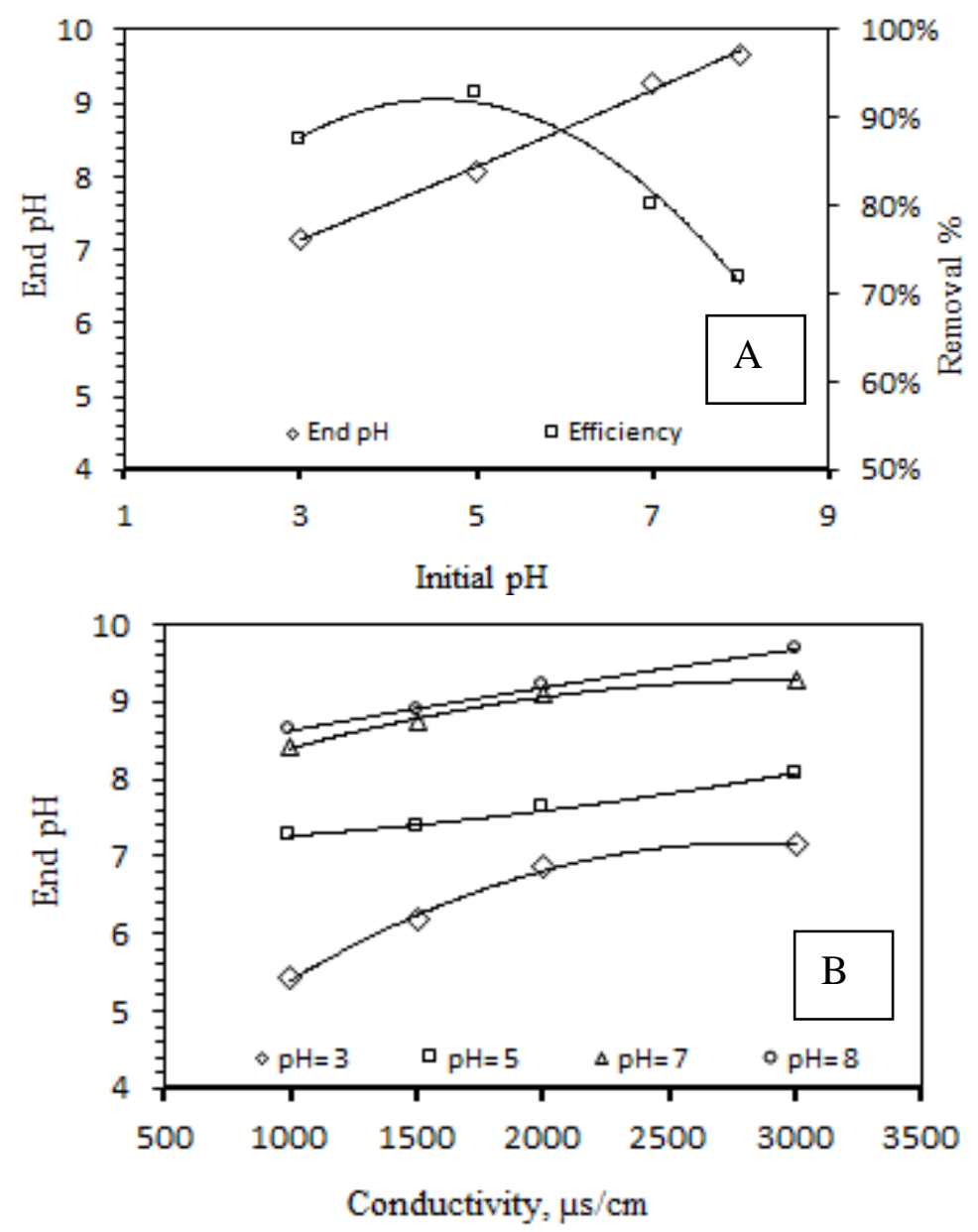

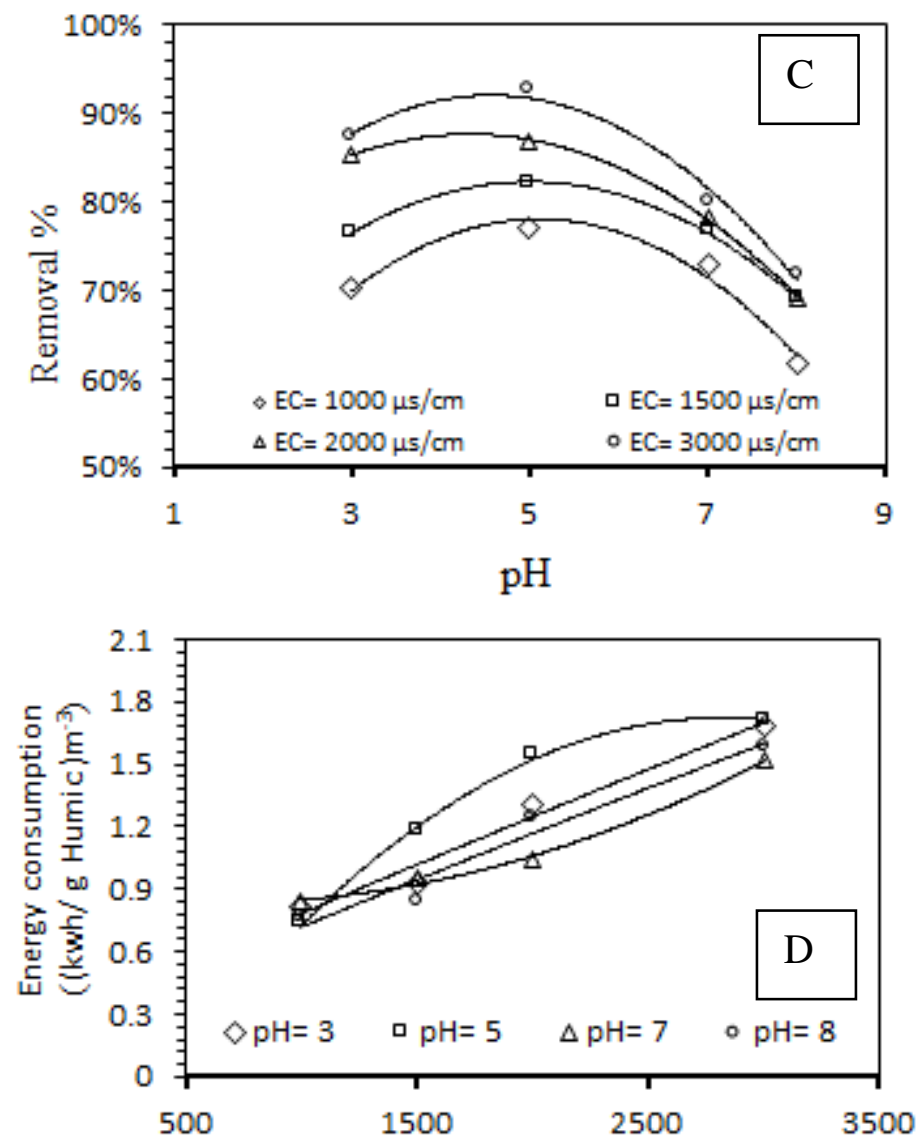

Conductivity, $\mu \mathrm{s} / \mathrm{cm}$

Figure 4. $\mathrm{pH}$ change during process(A), $\mathrm{pH}$ change at different initial electrical conductivity (B), HA removal in different $\mathrm{pH}$ and electrical conductivity $(\mathrm{C})$, Electrical consumption in different $\mathrm{pH}$ and electrical conductivity (D) (EC $3000 \mu \mathrm{S} / \mathrm{cm}$, HA $20 \mathrm{mg} / 1,50 \mathrm{~V}, \mathrm{pH}$ 5, Time 80)

Considering the fact that the ultimate $\mathrm{pH}$ values raised up to 7.15 and 8.07 from initial values equal to 3 and 5, respectively, and since this water may be used at later steps of the water treatment without performing secondary $\mathrm{pH}$ adjustments, it is reasonable to apply these values as the most appropriate option.

\section{CONCLUSION}

In this study, removal efficiency of humic acid extracted from natural aqueous media was investigated by electrocoagulation process. Results of the experiments indicated that variables such as $\mathrm{pH}$, electric conductivity, and reaction time influence the removal efficiency of humic acid remarkably, and when the rate of electric conductivity enhances and the $\mathrm{pH}$ values of the aqueous media were set to acidic range close to the neutral value, the removal efficiency increases compared to other conditions. The maximum efficiency was achieved in synthetic samples and electric conductivity of $3000 \mu \mathrm{s} / \mathrm{cm}, \mathrm{pH} 5$, reaction time of $80 \mathrm{~min}$ and potential difference of $50 \mathrm{~V}$. The initial amount of 
$20 \mathrm{mg} / \mathrm{L}$ of humic acid with energy and electrode weigh consumptions equal to $1.71 \mathrm{~kW} / \mathrm{h}$ for every $\mathrm{g}$ of the removed humic acid per cubic meter and $0.19 \mathrm{~kg}$ for every gram of humic acid per cubic meter, respectively, reached to $1.46 \mathrm{mg} / \mathrm{L}$ in with $92.59 \%$ decrease in the output. In general, these results demonstrate that, the electrocoagulation process equipped with iron electrodes was remarkably effective on the removal of humic acid, and may attract attentions and be utilized as a convenient and cost-effective method in removal of humic acid from aqueous media.

\section{ACKNOWLEDGMENTS}

The authors are grateful for the financial support of this project by the health research deputy of Gonabad University of Medical Sciences and technical support during this study with code of 94/56. Likewise, we should thank the scientific cooperation of Mohammad Mehdi Baneshi, Mohammad Mobini, Amin Zarei, Gholamreza Ebrahimzadeh, Ahmad Reza Yari, Ehsan Abouee Mehrizi and Mohsen Poursadeghiyan.

\section{ETHICAL ISSUE}

Ethical issues entirely have been considered by the authors and desperately tried to avoid plagiarism.

\section{CONFLICT OF INTEREST}

Authors declare that there is no conflict of interests.

\section{References}

1. H. Biglari, M. Saeidi, V. Alipour, S. Rahdar, Y. Sohrabi, R. Khaksefidi, M.R. Narooie, A. Zarei and M. Ahamadabadi, Int. J. Pharm. Technol., 8 (2016) 17856.

2. E. Bazrafshan, A. Joneidi Jaafari, F. Kord Mostafapour and H. Biglari, Iran. J. Heal. Environ., 5 (2012) 211.

3. M.C. Brum and J.F. Oliveira, Miner. Eng., 20 (2007) 945.

4. M. Karimaei, K. Sharafi, M. Moradi, H.R. Ghaffari, H. Biglari, H. Arfaeinia and N. Fattahi, Anal. Methods, 9 (2017) 2865.

5. M. Ahamadabadi, M. Saeidi, S. Rahdar, M.R. Narooie, A. Salimi, V. Alipour, R. Khaksefidi, M.M. Baneshi and H. Biglari, Res. J. Appl. Sci., 11 (2016) 1399.

6. D.A. Fearing, J. Banks, S. Guyetand, C.M. Eroles, B. Jefferson, D. Wilson, P. Hillis, A.T. Campbell and S.A. Parsons, Water Res., 38 (2004) 2551.

7. S. Mohammadi, E. Zamani, Z. Mohadeth, F. Mogtahedi, H. Chopan, F. Moghimi, M. Mohammadi, M. Karimi, H. Abtahi and K. Tavakkoli, Pharm. Sci., 20 (2015) 157.

8. M. Moradi, Y. Safari, H. Biglari, M. Ghayebzadeh, M. Darvishmotevalli and M. Fallah, Int. J. Pharm. Technol., 8 (2016) 17975.

9. K. Sharafi, M. Fazlzadehdavil, M. Pirsaheb, J. Derayat and S. Hazrati, Ecol. Eng., 44 (2012) 244.

10. H. Biglari, M. Saeidi, S. Rahdar, M.R. Narooie, A. Salimi, R. Khaksefidi, M.M. Baneshi, M. Ahamadabadi and V. Alipour, IIOAB J., 7 (2016) 523.

11. M. Mirzabeygi, M. Naji, N. Yousefi, M. Shams, H. Biglari and A.H. Mahvi, Desalin. Water Treat., (2016) 1.

12. Y. Yoon and R.M. Lueptow, J. Memb. Sci., 261 (2005) 76.

13. S. Rahdar, R. Khaksefidi, V. Alipour, M. Saeidi, M.R. Narooie, A. Salimi, H. Biglari, M.M. Baneshi and M. Ahamadabadi, IIOAB J, 7 (2016) 536.

14. S.-C. Fan, Y.-C. Wang, C.-L. Li, K.-R. Lee, D.-J. Liaw, H.-P. Huang and J.-Y. Lai, J. Memb. Sci., 204 (2002) 67.

15. W.-J. Huang, L.-Y. Chen and H.-S. Peng, Environ. Int., 29 (2004) 1049. 
16. M. Pirsaheb, T. Khosravi, K. Sharafi, L. Babajani and M. Rezaei, World Appl. Sci. J., 21 (2013) 416.

17. B. Edris, B. Hamed and M. Ferdoskord, Heal. Scope, 2012 (2012) 25.

18. A. Matilainen, M. Vepsäläinen and M. Sillanpää, Adv. Colloid Interface Sci., 159 (2010) 189.

19. X. Zhang and R.A. Minear, Water Res., 40 (2006) 221.

20. N.U. Benson, O.A. Akintokun and A.E. Adedapo, J. Environ. Public Health, 2017 (2017)

21. S. Mazloomi, R. Nabizadeh, S. Nasseri, K. Naddafi, S. Nazmara and A. Mahvi, J. Environ. Heal. Sci. Eng., 6 (2009) 301.

22. B. Skjelkvåle, J. Stoddard, D. Jeffries, K. Tørseth, T. Høgåsen, J. Bowman, J. Mannio, D. Monteith, R. Mosello and M. Rogora, Environ. Pollut., 137 (2005) 165.

23. J. Vuorenmaa, M. Forsius and J. Mannio, Sci. Total Environ., 365 (2006) 47.

24. V. Alipour, L. Rezaei, M.R. Etesamirad, S. Rahdar, M.R. Narooie, A. Salimi, J. Hasani, R. Khaksefidi, S.A. Sadat and H. Biglari, J. Glob. Pharma Technol., 9 (2017) 40.

25. H. Biglari, M. Afsharnia, V. Alipour, R. Khosravi, K. Sharafi and A.H. Mahvi, Environ Sci Pollut Res Int, 24 (2017) 4105.

26. R. Khosravi, H. Hossini, M. Heidari, M. Fazlzadeh, H. Biglari, A. Taghizadeh and B. Barikbin, Int J Electrochem Sci, 12 (2017) 4745.

27. M. Pirsaheb, M. Moradi, H. Ghaffari and K. Sharafi, Int J Pharm Technol, 8 (2016) 11023.

28. S. Rahdar, M. Ahamadabadi, R. Khaksefidi, M. Saeidi, M.R. Narooie, A. Salimi, H. Biglari and M.M. Baneshi, J. Glob. Pharma Technol., 9 (2017) 20.

29. A. Beagles, Green Pages, (2004)

30. H. Biglari, A. Chavoshani, N. Javan and A. Hossein Mahvi, Desalin. Water Treat., (2016) 1.

31. M.F. Ni'am, F. Othman, J. Sohaili and Z. Fauzia, Malaysian J. Anal. Sci., 11 (2007) 198.

32. M. Pirsaheb, T. Khosravi, K. Sharafi and M. Mouradi, Desalin. Water Treat., 57 (2016) 5391.

33. C.W. Chow, J.A. Van Leeuwen, R. Fabris and M. Drikas, Desalination, 245 (2009) 120.

34. Q.-Y. Feng, X.-D. Li, Y.-J. Cheng, M. Lei and Q.-J. Meng, J. China Univ. Min. Technol., 17 (2007) 513.

35. X. Zhan, B. Gao, Q. Yue, Y. Wang and Q. Wang, Chem. Eng. J., 161 (2010) 60.

36. E. Bazrafshan, H. Biglari and A.H. Mahvi, E-Journal Chem., 9 (2012) 2453.

37. M. Klavins and L. Eglite, Colloids Surfaces A Physicochem. Eng. Asp., 203 (2002) 47.

38. W.E. Federation and A.P.H. Association, Am. Public Heal. Assoc. Washington, DC, USA, (2005)

39. E. Bazrafshan, H. Biglari and A.H. Mahvi, Fresenius Environ. Bull., 21 (2012) 364.

40. A.P.H. Association, Standard methods for the examination of water and wastewater, 20 (1998)

41. A.S. Koparal, Y.Ş. Yildiz, B. Keskinler and N. Demircioğlu, Sep. Purif. Technol., 59 (2008) 175.

42. O. Abdelwahab, N. Amin and E.Z. El-Ashtoukhy, J. Hazard. Mater., 163 (2009) 711.

43. N. Adhoum and L. Monser, Chem. Eng. Process. Process Intensif., 43 (2004) 1281.

44. M.M. Emamjomeh and M. Sivakumar, J. Environ. Manage., 90 (2009) 1204.

(C) 2018 The Authors. Published by ESG (www.electrochemsci.org). This article is an open access article distributed under the terms and conditions of the Creative Commons Attribution license (http://creativecommons.org/licenses/by/4.0/). 